\title{
EL LABERINTO DEL HISTORIADOR. MILITANCIA Y REVOLUCIÓN EN EL ESPEJO DEL TIEMPO PRESENTE
}

\author{
Frédérique Langue \\ IHTP-CNRS
}

(France)

\author{
ORCID: https://orcid.org/0000-0002-0464-1388 \\ frederique.langue@cnrs.fr
}

Partiendo de conversaciones que tuvimos en el marco de nuestro centro de investigación, este ensayo retoma algunas de las problemáticas abordadas por Juan Carlos Garavaglia en su ultimo libro, Una juventud en los años sesenta (2015), especialmente el tema de la militancia. Hace bincapié en la relación memoria-bistoria y el peculiar estatuto del historiador en cuanto testigo y partícipe a la vez de una historia del tiempo presente de la que no se puede eximir, de sus análisis críticos de situaciones y procesos instrumentalizados por otros actores de la escritura de la historia en el espacio público, sobre todo los ideólogos y políticos, que poco tienen que ver con los «intelectuales orgánicos» de antaño.

PALABRAS CLAVE: militancia, revolución, historia del tiempo presente, América Latina, emociones.

\section{THE LABYRINTH OF THE HISTORIAN.}

\section{Militance and Revolution in the MirRor of Present Time}

Based on informal conversations we used to maintain in our late research center, this essay takes up some of the problems addressed by Juan Carlos Garavaglia in its latest book, Una juventud en los años sesenta (2015), especially the issue of militancy. It emphasizes the relation memory-history and the peculiar statute of the historian as a witness and participant at the same time of a bistory of the present time from which it can not break free. Il also focuses on its critical analysis of situations and processes instrumentalized by other actors of 
the writing of history in the public space, first and foremost the ideologues and politicians, quite unlike with the «organic intellectuals» of the past.

KEYWORDS: Militancy, Revolution, History of the present Time, Latin America, Emotions.

Hace varios años, cuando Juan Carlos Garavaglia dirigía el centro de investigación sobre mundos americanos de la EHESS (Cerma), tuvimos la oportunidad de intercambiar acerca del tema de la militancia, un tema que no llegó a desarrollar formalmente, aunque sí lo inscribió dentro del proyecto de historia de las sensibilidades que yo coordinaba en ese momento. Fue con la publicación de Una juventud en los años sesenta (2015) cuando Juan Carlos reincidió en el tema, desarrollándolo de forma magistral, lúdica y crítica a la vez, como acostumbraba hacerlo, aunque esta vez de una forma mucho más personal y hasta testimonial. En ese preciso momento, yo acababa de trasladarme al Instituto de historia del tiempo presente, dejando un centro de investigación donde el tiempo presente y la historia de las emociones que llevaba años rastreando en la larga duración no eran santos de las devociones, y donde la práctica interna de la democracia (Juan Carlos ya no estaba a cargo) resultaba notablemente mejorable.

Coincidimos casualmente en varios aspectos, y en un diagnóstico implacable, el del imprescindible compromiso del historiador con la democracia, su insoslayable implicación (con la salvedad de la distancia critica propia del método histórico) en debates a veces muy actuales. Podría hablar horas seguidas de los aportes de Juan Carlos a la historia moderna de América (historia «colonial»), desde la yerba mate a las estructuras agrarias de la región bonaerense, pasando por las alcabalas poblanas o temas de historia de América que tuvimos la oportunidad de abordar en recorridos científicos e incluso espaciales paralelos (i.e. las élites coloniales). Otros compañeros de andanzas o de archivos, de los que están reunidos en este homenaje lo harán sin lugar a dudas.

Por la trayectoria que ha sido la nuestra, y que compartimos en lo institucional y en nuestras últimas inquietudes, prefiero centrarme en el aspecto más reciente que acabo de comentar, el del estatuto del historiador en relación con un pasado no tan remoto, con persistentes ecos en el presente, teniendo en cuenta la característica quizás fundamental de la historia del tiempo presente: el historiador se convierte en testigo de la historia (no sólo de su propia historia como lo quiso hacer muy modestamente Juan Carlos), la está presenciando (con o sin distancia temporal, siendo ésta cada día más achicada por las nuevas tecnologías de la información) y experimentando a veces en carne propia, como bien lo demuestra a todas luces el último libro de Juan Carlos. De hecho, resulta ineludible el compromiso del historiador en defensa de la democracia, a favor de un «nunca más» y en recuerdo de «aquellos que fueron sumergidos en la noche sin fin» de la dedicatoria del libro, con la consiguiente adaptación de la fórmula a los lugares por donde llegó a transitar y a sentar biblioteca a falta de archivos personales. 


\section{El espejo}

En la carátula del libro (Una juventud en los años sesenta), Jorge Gelman puntualizó que no era un libro de historia, pese a ser este libro lo mejor que había leído últimamente. Por haberme convertido en historiadora del tiempo presente, comparto y no coincido a la vez con esta apreciación. El libro de Juan Carlos es en efecto un testimonio, y un testimonio de lo más auténtico. También tiene valor de análisis, de un análisis de lo mas acucioso para la historia del tiempo presente de Argentina, hasta se puede decir que «hace» historia, quizás porque éste no fue su propósito inicial. Indicó que se había distanciado de la «contaminación»—de acuerdo con Juan Carlos- que hubiesen inducido lecturas de especialistas del período, por más brillantes y sugerentes que fueran: «es innegable que este libro es un libro de memorias escrito por un historiador», sorteando además las «trampas» de la memoria y sus contradicciones. ${ }^{1}$ Recordamos que el testimonio, el testigo es la fuente predilecta de la historia del tiempo presente - los remito sobre el particular al libro epónimo la «era del testigo», que no deja de plantear además la cuestión muy sensible de la verdad - ${ }^{2}$ En este sentido, no fue baladí su primer propósito, el de escribir un libro de entrevistas a varios compañeros de una lucha que se extendiera de los años cincuenta hasta mediados de los setenta. Ahora bien, pese a la incuestionable legitimación científica del género desde los inicios del siglo XXI, y al vuelco epistemológico que supuso la historia del tiempo presente, no se atrevió a «cambiar casi completamente de orientación» como historiador. Resolvió contar «su «propia historia», buscando encontrar respuesta a unos interrogantes «latentes en (su) fuero interior»:

Hacer historia del tiempo presente es algo que no se improvisa no más, mal que les pese a algunos «publicistas» que suponen hablar sobre el pasado inmediato tiene reglas distintas a hacerlo sobre el siglo XVIII o XIX. ${ }^{3}$

Se adentra además en una experiencia vivencial y una problemática, no tanto de las revoluciones sino de la revolución. Cuando ésta se ha visto falseada y desvirtuada en las ultimas décadas, tanto en América latina como en Europa, con el supuesto derrumbe de las ideologías aunque no de los ideólogos disfrazados de populistas para el electorado y de expertos auto proclamados en el escenario mediático. Maltrecha, aunque de lo más presente en el imaginario social y político (¿bajo forma de ideales transgredidos?) si les prestamos alguna que otra atención a los «herederos» de la gesta y del relato revolucionarios. ${ }^{4}$

1. Garavaglia, Juan Carlos, Una juventud en los años sesenta, Buenos Aires, Prometeo Libros, 2015, p. 13.

2. Wievorka, Annette, L'ère du témoin, Paris, Pluriel, 2013; Voldman, Danièle, «Le témoignage dans l'histoire du temps présent», Bulletin de l'IHTP, n. ${ }^{\circ}$ 75, julio 2000, Dossier - L'histoire du temps présent, hier et aujourd'hui, <http://www.cmtra.org/avec/lib/elfinder-2.0-rc1/files/NOS\%20ACTIONS/Publications/Dossiers $\% 20$ documentaires/Archives $\% 20$ sonores/la $\% 20$ fabrique $\% 20$ du $\% 20$ témoin/VOLDMAN_Institut $\% 20$ d\%20histoire\%20du\%20temps\%20présent \%20-\%20IHTP\%20-\%20Le\%20témoignage\%20dans \%201\%20 histoire \%20française \%20du\%20temps \%20présent.pdf $>$.

3. Garavaglia, J. C., Una juventud en los años sesenta, cit., p. 12.

4. Debray, Laurence, Fille de révolutionnaires, Paris, Stock, 201 (trad. esp. 2018, Hija de revolucionarios, Barcelona, Anagrama, 2018). 
Militancia, precisamente: con este término y su valoración en términos de vivencia personal, tuve la oportunidad de adentrarme en un pasado reciente que me había tocado experimentar y luego estudiar en condiciones bochornosas por no decir kafkianas: Chávez, una Venezuela en la que me había tocado vivir por largo tiempo, a diferencia de los seudo expertos universitarios (o de cualquier otra procedencia) que pululan desde que Venezuela se puso de moda, un país que solo dejé por azares del destino pero esto es otra historia. Respecto a Chávez, siempre recordaré las palabras de un Juan Carlos apenado cuando ganó las elecciones en diciembre de 1998. Me dijo más o menos en estos términos: éste no es sino un «caudillo», esto no va por el buen camino, no va a salir bien.

No había sido otra la interpretación propugnada por el periodista y diplomático venezolano Carlos Rangel en 1976, con motivo de la publicación de su libro Del buen Salvaje al Buen Revolucionario, cuando su «diagnóstico de Bolívar» hacía hincapié en el papel del caudillismo y por lo tanto en el «partido militar», en la historia de su país. El muy lúcido C. Rangel avisaba en el «mito» del «buen salvaje» el anclaje de otro mito, de otro liderazgo y de otra tiranía, con un «buen revolucionario» llamado a salvar a Latinoamérica, así del imperialismo... Historiador y filósofo a la vez, Rangel rechazó el victimismo de cuño nacionalista que le echa la culpa del «subdesarrollo» a otras naciones y apuesta por una identidad latinoamericana radicalmente distinta a la de Occidente. Para la pequeña historia, este libro que, en su momento, fue un poco como la antítesis del libro Las venas abiertas de América Latina (1971, de Eduardo Galeano, un ícono de la izquierda latinoamericana), se tradujo a numerosos idiomas (cuenta con no más de 16 ediciones en español). A los 30 años de publicarse esta visionaria reflexión, el despiadado análisis fue reeditado en español, con un epílogo (2006) del analista cubano Carlos Alberto Montaner.5

Otra fórmula de Juan Carlos que recordé y tuve la oportunidad de meditar a lo largo de estos años que dediqué a las desventuras de la democracia venezolana en medio de los deslices ideológicos «hexagonales»: si la comparamos con Europa, la «desventaja» de América Latina radica en la ausencia, en la debilidad y/o extrema variabilidad del «Estado de derecho...». Cuando se sabe que el debate en torno a la historia del tiempo presente no se ciñe a cuestiones de legitimidad científica como fue el caso en los años ochenta del siglo XX, que ya no versa sobre la posibilidad de la misma sino en la caracterización del periodo considerado junto a posibles matices y periodizaciones internas dentro de éste, dicho de otra forma en sus retos e imprescindible vigilancia ante los usos políticos del pasado en incluso la «obsesión por el pasado», resultan aún más agudas las observaciones hecha por Juan Carlos así como el tratamiento de los «años sesenta», en su valioso testimonio. La postura historiográfica y epistemológica de la historia del tiempo presente encierra en efecto una insuperable evidencia: se escribe partiendo del presente y desde el presente, en una suerte de historia regresiva tan preciada de otro colega nuestro, Nathan Wachtel. ${ }^{6}$

5. Rangel, Carlos, Del buen Salvaje al Buen Revolucionario, Caracas, Monte Ávila, 1976.

6. Garcia, Patrick, «Essor et enjeux de l'histoire du temps présent au CNRS», La revue pour l'bistoire du 
Sendas consideraciones me llevaron a los cuestionamientos que fueron y siguen siendo en gran parte los de la historia del tiempo presente, de su epistemología y del estatuto del historiador fundamentalmente, o mejor dicho los reforzaron ya que siempre estuve oscilando entre una historia remota (al dedicarme a la historia social y cultural de América española en México y luego Venezuela) y el maltrecho siglo XX y sus avatares revolucionarios en el siglo XXI. También tuve que enfrentar la dificultad en determinados momentos de defender una compostura democrática y de mantener una mirada crítica de izquierda ante movimientos y líderes que dejaron de serlo, aunque inicialmente sí fueron portadores de muchas esperanzas. Las revoluciones funcionan en un modo binario, uno está a favor o está en contra, no hay término medio como lo indicó el propio Chávez. Se nutren del resentimiento y de la violencia ajena y propia (de acuerdo con un especialista del tema, Marc Ferro). ${ }^{7}$

Cuando además la aprensión de una actualidad lejana se da en una Europa donde pervive un imaginario romántico respecto a este tipo de proceso y predominan expertos sin más experiencia vivencial del lugar que unos viajecitos ideológicos (gran tradición izquierdista de la que Cuba, y luego la Nicaragua de la Revolución sandinista, la de 1979, supieron sacar el mejor provecho), se entiende mejor el porqué de semejantes equivocaciones y luego de repentinos cambios de juicio y arrepentimientos (en el mejor de los casos). En 1989, otro libro «realista», el de J. Verdés-Leroux, La lune et le caudillo («La luna y el caudillo»), no despertó mayores preguntas acerca de la revolución por antonomasia, la Revolución cubana, en el microcosmos intelectual, hasta la salida de un ex primer ministro francés luego de unas cuantas ejecuciones de disidentes en la isla (2003), acerca de «la extraña mansedumbre» que rodeaba la Revolución y nutrió lo que llamó «la fe de los vencidos». ${ }^{8}$ Sólo el tiempo y los análisis rigurosos pueden acabar, dar al traste con esa ceguera intelectual y en gran parte ideológica, que corre parejas con una ignorancia del país y un sectarismo ideológico de que se creía con sobradas ilusiones que pertenecía al pasado.

Otro elemento, fundamental a la hora de considerar los resortes del acontecer histórico y de su incorporación a posteriori en un imaginario político si no ideológico, lo constituyen las emociones. Al ser testigo y a veces partícipe de los procesos que va analizando, el historiador del tiempo presente tampoco puede hacer caso omiso de su propia subjetividad, de un contexto social y cultural en que está inmerso. Los debates más recientes acerca de esta forma ahora legitima de enfocar o enfrentar incluso al pasado, de hacer historia aunque de una forma siempre irreverente y adversa a las interpretaciones/ historias oficiales cualesquiera que sean apuntan en este sentido. Basta con mencionar las últimas obras de Henry Rousso, Frente al pasado y La última catástrofe, esta de reciente

CNRS, n. ${ }^{\circ}$ 9, 2003, <http://journals.openedition.org/histoire-cnrs/562>. Henry Rousso, La hantise du passé. Entretien avec Philippe Petit, Paris, Textuel, 1998.

7. Ferro, Marc, Le Ressentiment dans l'histoire: Comprendre notre temps, Paris, Odile Jacob, 2007.

8. «L'étrange mansuétude», Le Nouvel Observateur, 19 juin 2003; Verdés-Leroux, Jeanine, La foi des vaincus. Les «révolutionnaires» français de 1945 à 2005, Paris, Fayard, 2005. 
aparición en castellano en Chile cuando se escriben estas líneas. ${ }^{9}$ Y más cuando el espacio público, sus redes sociales en especial, los medios de comunicación, amén de los políticos que erigen la memoria en patrimonio nacional — cuando los mismos enfoques historiográficos dejaron de ser estricta y llanamente nacionales- partiendo de una demanda social, participan de un manejo de las emociones, que se une a la instrumentalización del pasado. No he mencionado hasta ahora un fenómeno político y social que concentra todas estas problemáticas, el populismo, en su vertiente «de izquierda» o no ( $C f$. el manifiesto reciente de Chantal Mouffe, teórica de la «democracia agonística», acerca de un «populismo de izquierdas», y, antes, la «razón populista» de Ernesto Laclau). ${ }^{10}$ Es uno de los mayores protagonistas de esta historia, tanto en el escenario latinoamericano como lo puso de relieve Juan Carlos, como en Europa. De esta incómoda y ajetreada responsabilidad del historiador quisiera dar unas pistas, relacionadas con esta peculiar manera de escribir historia, y de que Juan Carlos, en su último libro, dio una excelsa muestra y no dejó de reafirmar en cuanto compromiso del historiador ante realidades traumáticas, dictaduras, represión, terrorismo de Estado, dicho de otra forma, ante «un pasado que no pasa» (H. Rousso). En la medida en que ya tuve la oportunidad de abordar estos paradigmas de la historia del tiempo presente en otros estudios, y especialmente su diferenciación respecto a la historia reciente (distinta en cuanto a epistemología y secuencia cronológica), tanto en el caso europeo como latinoamericano, ${ }^{11}$ me conformaré con recordar algunos puntos clave para la comprensión del fenómeno que nos interesa aquí, las azarosas relaciones entre militancia y revolución, sus avatares a lo largo del tiempo y por lo tanto, sus variopintos y muy actuales regímenes de historicidad, en contrapunto al libro de Juan Carlos Garavaglia. ${ }^{12}$

\section{«Nuestra América» y el «pasado presente» ${ }^{13}$}

De la historia del tiempo presente hay que recordar que está vinculada de forma muy estrecha al instituto del mismo nombre, el IHTP, creado en Francia en 1978 y heredero del Comité de historia de la Segunda Guerra Mundial (1951) en un doble contexto: el

9. Rousso, Henry, Face au passé, Paris, Belin, 2016 y La dernière catastrophe. L'histoire, le présent, le contemporain, Paris, Gallimard, 2012 (Ed. española Santiago de Chile, Editorial Universitaria, 2018).

10. Mouffe, Chantal, Pour un populisme de gauche, Paris, Albin Michel, 2018; Laclau, Ernesto, La razón populista, Buenos Aires, FCE, 2005; Langue, Frédérique y Edgardo Manero, «Repenser les populismes en Amérique latine et au-delà. Des figures du conflit à la guerre des mémoires», Revue ILCEA, n. ${ }^{\circ} 8,2013$, Université Stendhal, Grenoble 3, <https://journals.openedition.org/ilcea/2103>.

11. Langue, Frédérique, «Usos del pasado y guerra de las memorias en la Venezuela de la «Segunda Independencia», Polis, Revista Latinoamericana (Chile), n. ${ }^{\circ} 34$, avril 2013, <http://polis.revues.org/8953>; y «Un pasado que no pasa: emociones y salvación en la Venezuela del tiempo presente», Boletín Americanista, n. ${ }^{\circ} 72$, 2016, pp. 237-256, <http://revistes.ub.edu/index.php/BoletinAmericanista/article/view/16052>.

12. Hartog, François, Régimes d'historicité. Présentisme et expériences du temps, Paris, Seuil, 2003.

13. Noiriel, Gérard, «Le» passé/présent»: une approche différente de l'histoire du temps présent», en État, nation et immigration, Paris, Gallimard/Folio, 2005, pp. 70-101. 
despertar de una memoria europea e internacional de la Segunda Guerra Mundial y los grandes traumas del siglo xx. De ahí su papel rector en la emergencia de una historiografía de la Resistencia, de la Ocupación y de la colaboración (del llamado gobierno de Vichy, que dio pie a encendidos debates en relación con la coyuntura política del tiempo), y del conflicto militar a escala mundial. Dicho de otra forma, fue un intento - logrado si consideramos la legitimidad de la historia del tiempo presente hoy en día y sus múltiples ecos en América Latina - por estructurar el pasado «próximo», problematizar una «contemporaneidad» enfocada a partir de un acontecimiento traumático aunque definitorio del mundo europeo contemporáneo, la segunda Guerra Mundial. En este sentido, y a diferencia de otras ciencias sociales, la historia del tiempo presente contempla los usos políticos del pasado, la construcción social de la memoria, más precisamente de una memoria colectiva traumática, de un pasado «que no pasa» (su ecos en el presente, y se debate incluso en el espacio público, hoy en día también producto de la globalización e investido a veces por otros actores de la escritura de la historia (medios de comunicación, políticos, instituciones como la justicia, el ejército o la Iglesia, dependiendo del país etc.). ${ }^{14}$ En el caso de Brasil, de México, de Chile o de Argentina («historia del pasado reciente», «historia del presente», «historia del pasado vivo»), la historia del tiempo presente tampoco se conforma con ser otra historia contemporánea un poco más extendida. Empieza a cobrar mayor fuerza $y$ legitimidad en la década de los años 2000 bajo esta denominación, contribuyendo en renovar las problemáticas de la disciplina y en contextos de salida de una violencia política experimentada en el tiempo largo si no de dictaduras, aprovechando sus «transiciones» a la democracia, en las que el historiador presencia en vivo los hechos analizados y que el marco legal y político ahora sí facilita el acceso a los archivos así como la libre divulgación de las investigaciones. ${ }^{15}$

Ahora bien, y más allá de la «obsesión por el pasado» que en Europa derivó durante largas décadas de la experiencia traumática de la Segunda Guerra Mundial y de la Shoah (que desempeña el papel de matriz memorial), la historia del tiempo presente arroja características distintas en el continente latinoamericano. El historiador se enfrenta en efecto tanto con una «relación simbólica a la historia como con temporalidades diferenciales» aunque ocasionalmente paralelas en cuanto a cronologías se refiere. No se dan rupturas tan significativas como la segunda Guerra Mundial y sus secuelas de la Guerra Fría, sino conflictos de «escasa intensidad». Esto incluso en el caso de las «revoluciones» continentales, que desempeñan más bien un papel fundador en el imaginario continental (Revolu-

14. Delacroix, Christian; François Dosse, Patrick Garcia y Nicolas Offenstadt (dir.), Historiographies. Concepts et débats, Paris: Gallimard, coll. «Folio histoire», 2010, 2 vols.; Garcia, Patrick, «Essor et enjeux de l'histoire du temps présent au CNRS», La revue pour l'histoire du CNRS, n. ${ }^{\circ} 9-2003<$ http://histoire-cnrs.revues.org $/ 562>$.

15. Rousso, H., La dernière catastrophe..., cit., p. 15; Pérotin, Anne (coord.), Historizar el pasado vivo en América Latina, 2007, <http://www.historizarelpasadovivo.cl>. Sobre la globalización de las ideas revolucionarias y su aprensión en el tiempo largo, $C f$. Langue, Frédérique, «Cuba: d`un anniversaire oublié à la visite de Barack Obama», Le Huffington Post, 25/03/2016; <http://www.huffingtonpost.fr/frederique-langue/cuba-dunanniversaire-oublie-a-la-visite-de-barack-obama_b_9545488.html>. 
ción Mexicana de 1910, Revolución Cubana de 1959), siendo quizás la única excepción el genocidio guatemalteco en la década de los ochenta. Por eso mismo, las historias nacionales rebosan de figuras heroicas e incluso de unos «mitos fundacionales» arraigados en las historias nacionales y especialmente en las «revoluciones de Independencia» y guerras civiles del siglo XIX «republicano». De ahí el hecho de que las élites políticas se empeñaron en elaborar unas historias patrias/hagiografías de los padres fundadores de la nación, respaldando la difusión de interpretaciones «autorizadas» del pasado si no de «historias oficiales» que respaldan un «orden político»: de la Argentina de Bartolomé Mitre (18211906) a la Venezuela de la «segunda Independencia» de Hugo Chávez (1954-2013), pasando por el Paraguay del general Stroessner (1912-2006) y la Cuba martiana de Fidel Castro (1926-2016). ${ }^{16}$

Junto a la densidad simbólica de esta relación con la historia, hay que subrayar asimismo la omnipresente referencia identitaria (ocasionalmente con fundamentos indigenistas) que subyace en numerosas reivindicaciones políticas que buscan legitimar a los vencidos (no se trata aquí de las «víctimas» de la historia europea) en el tiempo largo e impulsar la escritura de una contra historia, en un movimiento revisionista continuo que, hasta mediados del siglo XX, se aprovechó de la ausencia de formación de profesionales de la historia o intentaron pasarlos por alto. No tienen otro significado unos cuantos episodios recientes que ilustraron esta recurrente tendencia propicia a las historias oficiales y carente de mirada crítica respecto a la experiencia de la dictadura militar $(C f$. el Manifiesto de los historiadores argentinos en contra de la creación del Instituto Nacional de Revisionismo Histórico Argentino e Iberoamericano Manuel Dorrego (2011) o los distintos manifiestos de los historiadores chilenos sobre el juicio a Pinochet). En este aspecto, las dinámicas memoriales actuales tienden a resaltar los distintos «procesos de democratización» así como la reconstrucción de la «memoria histórica»: ahí radica el papel de las Comisiones de la Verdad y de los defensores de los derechos humanos, la importancia del «perdón» (caso de la justicia chilena en 2014), dicho de otra forma los usos políticos del pasado, que, en determinados casos, arrojan una vertiente patrimonial a través de los museos destinados a conmemorar el «Nunca más» (caso del museo de la ESMA —Escuela de Mecánica de la Armada — en Argentina, o del muy debatido Museo de la Memoria y los Derechos Humanos en Chile). ${ }^{17}$

La historia del tiempo presente se diferencia aquí claramente del «deber de memo-

16. Capdevila, Luc, y Frédérique Langue (dir.), Entre mémoire collective et histoire officielle. L'bistoire du temps présent en Amérique latine, Rennes, Presses universitaires de Rennes, 2009, pp. 9-24.

17. Ibidem; «Historiadores presentan manifiesto sobre el juicio a la dictadura militar» (16/4/2007), en el portal de la Universidad de Chile <http://www.uchile.cl/noticias/40867/historiadores-presentan-manifiestosobre-juicio-a-la-dictadura-militar >, «La declaración de los historiadores» (Argentina, noviembre de 2011), texto completo en <https://nuevomundoradar.hypotheses.org/89294>; Gárate Château, Manuel, «Las polémicas en torno al Museo de la Memoria y los Derechos Humanos en Chile», Carnet de l'IHTP, 21/11/2015 $<$ https://ihtp.hypotheses.org/1350>; «La polémica por el Museo de la Memoria obliga a dimitir al ministro de Cultura de Chile», El País, 14/8/2018 < https://elpais.com/internacional/2018/08/13/america/1534177652 _330511.html>. 
ria» propio de los países europeos respecto al Holocausto. Hay que contar además con un cuarto actor de la escritura de la historia (aparte del historiador, del juez y de los medios de comunicación) no siempre presente en la Europa de la post-guerra: el militar, parte de ese «oscuro pasado» que las conmemoraciones de los Bicentenarios de las Independencias iberoamericanas hicieron revivir y revisitaron entre otras asignaturas pendientes (las «responsabilidades») y, en todo caso, dentro de unas persistentes e inconclusas «batallas por la memoria» — de una memoria cada día más globalizada—, la justicia y el reconocimiento de las víctimas. Lo demuestra sobradamente la historia del tiempo presente de un país otrora oasis de democracia en un continente abrumado por los regímenes autoritarios y dictaduras, Venezuela, de su «Bolívar del siglo XX/XXI» y de su «Segunda Independencia». En este último caso, los historiadores se rebelaron en contra del llamado «culto fundacional» o culto al «divino Bolívar», o sea el ofensivo «bolivarianismo» pregonado por el discurso oficialista tanto dentro como fuera de las fronteras nacionales. ${ }^{18}$

\section{Memoria, resistencia, emociones}

Si bien la memoria, en cuanto «conjunto de obligaciones morales y (...) serie de dispositivos políticos tendientes no sólo a perpetuar el recuerdo sino, sobre todo, a desarrollar el conocimiento, el reconocimiento y la reparación de los crímenes del pasado», puede ser también «la manifestación de un alto grado de madurez democrática» como lo puntualizó H. Rousso en una entrevista reciente a un diario chileno. ${ }^{19} \mathrm{Al}$ enfocar acontecimientos y experiencias traumáticas que han dejado huellas vivas, tanto en lo colectivo como a nivel de los individuos, no se exime de cierta fragilidad. En este sentido, el historiador del tiempo presente no puede pasar por alto los resortes emocionales de la misma, de ahí la referencia a los «regímenes emocionales/», en una perspectiva muy cercana a los «regímenes de historicidad» ejemplificados por François Hartog, en cuanto valor social que les corresponde a la articulación temporal pasado/presente/futuro, dicho de

18. Soler, Lorena, Paraguay, la larga invención del golpe. El stronismo y el orden político paraguayo. Buenos Aires, Imago Mundi, 2012; Allier Montaño, Eugenia, Batallas por la memoria. Los usos políticos del pasado en Uruguay. Montevideo, Trilce-UNAM, 2010; «Jueces chilenos piden perdón por sus «omisiones», en la dictadura de Pinochet», El País, 5/9/2014 <http://internacional.elpais.com/internacional/2014/09/05/actualidad/1378356025_053445.html>. Una definición del «deber de memoria», en Escudero Alday, Rafael (coord.), Diccionario de memoria histórica. Conceptos contra el olvido, Madrid, Catarata, 2011, pp. 15 y ss.; Langue, Frédérique, «Desafíos y retos de la historia del tiempo presente», Dalla Corte, Gabriela; Ricardo Piqueras; Meritxell Tous Mata (coords.), Construcción social y cultural del poder en las Américas, Barcelona, Universidad de Barcelona —Edición km 13774- Fundació Casa América Catalunya, 2015, pp. 12-32. <http://www.americat. cat/es/construccion-social-y-cultural-del-poder-en-las-americas_es>; Pino Iturrieta, Elías, El divino Bolivar. Ensayo sobre una religión republicana, Madrid, Ed. de la Catarata, 2003.

19. «La memoria ha pasado a ser un valor fundamental, un derecho humano», entrevista a Henry Rousso por Pablo Marín, La Tercera, 19/8/2018 < http://culto.latercera.com/2018/08/19/henry-rousso-historiadorfrances-la-memoria-ha-pasado-a-valor-fundamental-derecho-humano/>. 
otra forma la manera cómo una sociedad interpreta su pasado y llega a historizar su presente («presentismo»). Las memorias sensibles que afloran en la contemporaneidad latinoamericana participan de una relación muy viva con la historia del continente, su largo ciclo de represión y violencia política, de violaciones a los derechos humanos, confirmando una singularidad propia del mundo latinoamericano a lo largo de estas últimas décadas, la de una sinergia notable entre las movilizaciones políticas y el compromiso por la «memoria histórica», coyuntura que anticipó en muchos casos y de forma más sistemática los avances historiográficos o «revival», en la materia. El contexto emocional que se origina en un «pasado que no pasa» cuestiona sin lugar a dudas las modalidades de la movilización y posiblemente de la resiliencia, como lo pusieron de relieve los casos de Chile, Argentina o de Venezuela. El prisma emocional y su construcción discursiva adquieren especial relevancia a la hora de interpretar el imaginario político complejo que subyace en las viejas movilizaciones peronistas en la Argentina de la post guerra fría, en unos años setenta marcados por la designación del «enemigo», en el Chile de la transición «pactada» y más de las nuevas generaciones confrontadas al cuadragésimo aniversario del golpe de Estado y un «11 de septiembre emocional», o también en la Venezuela de una teleología revolucionaria que hace del resentimiento social su resorte principal, en un contexto de polarización social e indudable retroceso en términos de prácticas de la democracia. ${ }^{20}$

Es el sentido del itinerario propuesto por Juan Carlos al revisitar la Argentina peronista y montonera de la década de los cincuenta, a través del filtro («milagroso») de la memoria o mejor dicho de la anamnesis, desde el fervor de la «militancia», en las izquierdas de los años sesenta, las confrontaciones con la injusticia (desde los 8 años), la incipiente lucha armada y clandestinidad incluidas (la montonera), la cárcel también a raíz de unas protestas callejeras, y, ante la represión militar y la imposibilidad para los militantes de izquierdas de llevar una carrera universitaria en ciencias sociales, el exilio en Europa, primero en España, luego en Francia y México, después de su estadía militante en la universidad de Bahía Blanca compaginando «lucha clandestina y función pública» y en los barrios de la ciudad antes de que el «infierno» se desatara en la Universidad del Sur. Una juventud en los años sesenta recoge asimismo y con una profusión de detalles la experiencia de las divisiones internas entre peronistas luego de la desaparición de Perón, la violencia paraestatal, la profundización de la represión, su distanciamiento respecto a la «Orga», sus «admoniciones morales» y su «militarización creciente», la clandestinidad en Buenos Aires junto a exilados uruguayos, chilenos o bolivianos. Hasta esta experiencia del miedo que lo lleva a huir de Argentina cuando culminó los discursos y las prácticas violentas, con del golpe de Estado (1976), sendas etapas que se benefician de ilustracio-

20. Capdevila, Luc, y Frédérique Langue (dir.), Le passé des émotions. D’une histoire à vif Amérique latine et Espagne, Rennes, PUR, 2014, p. 198, y las contribuciones sobre Chile (Manuel Gárate Chateau), Argentina (Moira Cristiá), Uruguay (María Laura Reali) o Paraguay (Luc Capdevila) y Venezuela (Frédérique Langue). Franco, Marina, Un enemigo para la nación, Orden interno, violencia y «subversión», 1973-1976, Buenos Aires, FCE, 2012. 
nes, fotos de prensa o procedentes de instituciones estatales y a veces inéditas (el Archivo Gráfico del AGN), que fueron, dicho sea de paso, «una forma peculiar de volver a vivir esas circunstancias» y también de acercarse un proceso de manera diferente, gracias a esa forma de «escritura visual sobre el pasado». ${ }^{21}$

La dimensión emocional está presente a lo largo de los diez capítulos: fervor, exaltación, optimismo de una juventud que aspiraba a cambiar el mundo, imaginando que «algún líder excepcional (como veíamos nosotros a Fidel) vendría en algún momento a construir un frente que incluyera al peronismo y a la izquierda», camino al socialismo. Un entusiasmo vinculado a la Revolución Cubana, «evento ideológico de la izquierda latinoamericana, europea y estadounidense», y «espectáculo de ideas» para el mundo occidental (R. Rojas). Ilusiones retrospectivamente, «actos de magia social» que llevaron a muchas muertes y desapariciones, a muchos exilios «interiores y exteriores». Pero también miedo, tristeza y dolor cuando los compañeros de lucha se van, víctimas de la represión, asesinados, cuando la «caída de Allende y el posterior desastre chileno (que) fue para (ellos) una auténtica catástrofe», el quiebre del juego democrático por medio de un golpe militar fomentado desde Estados Unidos en la continuación de los de Guatemala y Santo Domingo (señalando cuánto ha cambiado la relación de América Latina con Estados Unidos desde el fin de las dictaduras, «como se ve por los acontecimientos de Venezuela»...). También saca a colación el entusiasmo que sintió desde muy joven por la discusión política, el recuerdo de los enfrentamientos con la extrema-derecha peronista, o también de la retirada de la «Orga» de los escenarios de lucha, en fin, de la «durísima vida de militante total», encierro y aislamiento incluidos. Tampoco pasa por alto «las dificultades que había en la Orga para la discusión», en un ambiente de debate intelectual interno, apoyado por un grupo de intelectuales de afuera pero sin tener en cuenta el parecer de los «militantes de base», y su final salida de la organización a partir de 1974 y luego del país. En este sentido, y volvemos a las consideraciones que introdujeron este trabajo, y ante el silencio de las memorias militantes, el libro se convierte en un testimonio de desilusión y desengaño respecto a una izquierda «radical» que se refugió en la ideología más que en sus bases sociales y militantes, y de cierta forma, las traicionó, aunque en un contexto de terror y de violencia extrema —el periodo de represión que se afianzó entre 1973 y 1976, la dictadura militar 1976-1983 y la represión de la guerrilla o «subversión», un tema que el mismo Perón por lo tanto tampoco desconoció- que se cobró la vida de numerosos campesinos, obreros y sindicalistas. Participa de cierta forma de la desconstrucción del relato peronista y de su relativa responsabilidad en la imposición del lópezreguismo aunque no de organizaciones represivas como la Triple A, tal como se evidenció en varios trabajos de historia «reciente».22

A la luz de estas investigaciones recientes, y de testimonios como éste, quedó estable-

21. Garavaglia, J. C., Una juventud.., cit., pp. 15, 20, 32, 35, 45-46.

22. Garavaglia, J. C., Una juventud..., pp. 47-48, 50 (el subrayado es de JCG), 61, 115, 179 y ss. Rojas, Rafael, «Anatomía del entusiasmo: la revolución como espectáculo de ideas», América Latina Hoy, n. ${ }^{\circ}$ 47, 2009, $<$ http://revistas.usal.es/index.php/1130-2887/article/view/2048>. 
cida la responsabilidad del «viejo caudillo en el proceso de eliminación de las organizaciones armadas y de la izquierda juvenil del peronismo», así como el «engranaje represivo puesto en marcha contra la izquierda de su partido y para contener la movilización social y obrera». De tal forma que la historia oficial ya no puede contrarrestar el resquebrajamiento de consenso histórico difuso», el que consiste en establecer el «corte interno del peronismo tardío» entre Perón e «Isabelita», cuando los trabajos recientes ubicarían el punto de quiebre entre el gobierno de Héctor Cámpora y los gobiernos peronistas siguientes. Tampoco se puede silenciar la continuidad de ciertas prácticas represivas (y disciplinarias), como parte del proceso de instauración del terrorismo de Estado y de un ciclo represivo que abarca toda la década de 1970», lo que no deja de plantear la cuestión de la difusión en la opinión pública de las representaciones políticas en torno al «enemigo subversivo», aunque se diferencia del terrorismo de Estado implementado luego de forma sistemática por la dictadura militar. Un largo trabajo de memoria les queda por hacer a los historiadores del tiempo presente para desterrar para siempre el horror, de ahí la necesidad de romper el silencio para luchar contra el olvido. A ello contribuye este testimonio y otros muchos que participan tanto de la salida de conflictos y regímenes dictatoriales como de «transición» y preservación de la democracia (recién) restablecida, con el consiguiente balance de esos años trágicos. ${ }^{23}$

Dentro de ese contexto, Una juventud en los años sesenta plantea no sólo la necesidad de la labor del historiador en contra de visiones «autorizadas»/oficiales del pasado sino también la relativización del tema y del ideal o sueño inconcluso de revolución, partiendo tanto de una experiencia propia una biografía con sus contradicciones como reza el primer capítulo - y su «racionalidad retroactiva»— como de una reflexión histórica asentada en una metodología y una epistemología crítica (aunque no dirigida inicialmente hacia un periodo reciente). Se señaló en este aspecto que la movilización de pasiones mayoritariamente negativas y repetidas (resentimiento, odio), hacían de las revoluciones «una de las expresiones extremadas del resentimiento», sin por eso conferirle a esta emoción (el resentimiento) un valor exclusivamente negativo si nos referimos a los ejemplos tomados de la historia europea y el valor de «pasión social» que le corresponde. En otra escala, la de las revoluciones que llegaron al poder mediante líderes carismáticos. Basta con recordar que al mismo presidente Chávez se le decía el «mago de las emociones» cuando ganó las elecciones de 1998 y que el intento de golpe de Estado el 4 de febrero de 1992 fue durante muchos años para el imaginario izquierdista la «rebelión de los ángeles» (de acuerdo con el libro de la ex guerrillera Angela Zago), destacando el fervor que en sus primeros tiempos, tiende a acompañar las revoluciones así como la dimensión teleológica, si no religiosa de las mismas. ${ }^{24}$

23. Franco, Marina, Un enemigo para la nación..., cit., pp. 20-21, 29; J. C. Garavaglia, Una juventud..., cit., p. 208.

24. Garavaglia, J. C., Una juventud..., cit., p. 13; Mac Ferro, Le ressentiment dans..., cit., pp. 43 y ss.; Guénard, Florent, Le ressentiment passion sociale. Rennes, PUR, 2012, pp. 77 y ss.; Uzcátegui, José Luis, Chávez, mago de las emociones. Análisis psicosocial de un fenómeno político, Caracas, Lithopolar Gráficas, 1999; 
El fracaso in fine de los procesos revolucionarios, especialmente en el área que nos interesa (con el último caso trágico de Nicaragua), el regreso de las (ultra) derechas en el Cono Sur y más aún en Brasil luego de un primer siglo XX de las «nuevas izquierdas latinoamericanas», donde coexistieron sin embargo dos izquierdas (la democrática, y otra de cuño más autoritario) se contraponen a un resquebrajamiento de los mitos afines (i.e. el mito bolivariano, ampliamente retocado para usos discrecionales del nuevo salvador de la nación y hasta «del mundo», como lo pregonó Hugo Chávez desde la tribuna de la ONU en 2006, y su «historia oficial» dada a conocer desde un «Centro Nacional de la Historia»). En esta configuración continental, el mito revolucionario por excelencia, la Revolución cubana, dejó de ser — salvo en unas pocas excepciones militantes productos de una ideología de antaño- el modelo a seguir para los demócratas del planeta pese a la vigencia del discurso anti imperialista a lo largo y ancho del continente y a una seudo conciencia histórica, muy presente en extremas izquierdas occidentales ciegas ante la imposición de dictaduras disfrazadas de revolucionarias o de «democracias electorales» («democraturas»). ${ }^{25}$

Por la invalorable convergencia de los temas de la democracia y de la memoria en el mundo occidental, y habida cuenta de que se les considera incluso «sociedades de memoria» (Ricardo García Carcel), resulta fundamental el aporte de testimonios como este, desde dentro y con la mirada crítica del historiador ante las esperanzas quebradas e incluso de las «lágrimas» y de la melancolía que se esconden en estas páginas. Junto al lugar cada día más importante de los crímenes del pasado en las sociedades contemporáneas y el surgimiento de un espacio memorial más amplio, globalizado, aunque con el respaldo de una justicia internacional, pone de relieve el hecho de que los nuevos regímenes memoriales coinciden con frecuencia con el inicio de procesos de transición democrática y de cuestionamientos hacia el pasado. Por eso mismo, y a diferencia de la historia oficial, no se derivan de un modelo único y exclusivo, como lo demuestra el choque con dispositivos identitarios concurrentes e imaginarios nacionales aún presentes. La memoria, tanto en lo colectivo como en lo particular e individual, se convirtió en un valor casi universal encarnado en lugares simbólicos y el olvido en una postura condenable por la impunidad que propicia. Un valor cuanto más imprescindible, el de la «justa memoria» enaltecida por Paul Ricœur, cuando en la memoria de larga duración y las representaciones del pasado, si se les pasa por alto o deja que se instrumentalicen en excesivo — es el llamado «activismo memorial»-, puede originarse el resentimiento catalizador de un posible conflicto o catástrofe. Dentro de esta «justa memoria», convertida en «virtud cardinal de nuestro tiempo», hay que ubicar, a nuestro parecer, el valioso testimonio de Juan Carlos Garavaglia..6

Zago, Angela, La rebelión de los ángeles, Caracas, Warp Ediciones, 1998 (4a ed.). (El subrayado es nuestro).

25. Langue, Frédérique, «Bolivarianismos de papel», monográfico «El pasado en el presente: lecturas del bolivarianismo y su impacto internacional» (coord.), Manuel de Paz, Revista de Indias, vol. LXXVII, n. ${ }^{\circ} 270$, 2017, pp. 357-378 <http://revistadeindias.revistas.csic.es/index.php/revistadeindias/article/view/1047/1119>.

26. García Cárcel, Ricardo, La herencia del pasado. Las memorias bistóricas de España, Barcelona, Galaxia Gutenberg, 2012. Un ensayo contra el abuso de la memoria gana el Premio Nacional de Historia, El País, 27/11/2012 <https://elpais.com/cultura/2012/11/27/actualidad/1354017632_670374.html>; Rousso, H., Face 


\section{Prensa}

«Jueces chilenos piden perdón por sus «omisiones», en la dictadura de Pinochet», El País, 5/9/2014 $<$ http://internacional.elpais.com/internacional/2014/09/05/actualidad/1378356025_053445. html>.

«La memoria ha pasado a ser un valor fundamental, un derecho humano», entrevista a Henry Rousso por Pablo Marín, La Tercera, 19/8/2018 <http://culto.latercera.com/2018/08/19/henry-rousso-historiador-frances-la-memoria-ha-pasado-a-valor-fundamental-derecho-humano/> . «Un ensayo contra el abuso de la memoria gana el Premio Nacional de Historia», El País, 27/11/2012 <https://elpais.com/cultura/2012/11/27/actualidad/1354017632_670374.html>.

«Historiadores presentan manifiesto sobre el juicio a la dictadura militar» (16/4/2007), en el portal de la Universidad de Chile <http://www.uchile.cl/noticias/40867/historiadores-presentan-manifiesto-sobre-juicio-a-la-dictadura-militar $>$.

Entrevista a Henry Rousso, «Le surinvestissement dans la mémoire est une forme d'impuissance», Libération, 8/4/2016, <https://www.liberation.fr/debats/2016/04/08/henry-rousso-le-surinvestissement-dans-la-memoire-est-une-forme-d-impuissance_1444888>.

«L'étrange mansuétude», Le Nouvel Observateur, 19 juin 2003.

«La declaración de los historiadores» (Argentina, noviembre de 2011), texto completo en $<$ https:// nuevomundoradar.hypotheses.org/89294>.

«La polémica por el Museo de la Memoria obliga a dimitir al ministro de Cultura de Chile», El País, 14/8/2018 <https://elpais.com/internacional/2018/08/13/america/1534177652_330511. html>.

\section{Bibliografía}

Allier Montaño, Eugenia, Batallas por la memoria. Los usos políticos del pasado en Uruguay. Montevideo, Trilce-UNAM, 2010.

Capdevila, Luc, y Frédérique Langue (dir.), Entre mémoire collective et histoire officielle. L’histoire du temps présent en Amérique latine, Rennes, Presses universitaires de Rennes, 2009.

—, Le passé des émotions. D'une histoire à vif Amérique latine et Espagne, Rennes, PUR, 2014.

Debray, Laurence, Fille de révolutionnaires, Paris, Stock, 201 (trad. esp. 2018, Hija de revolucionarios, Barcelona, Anagrama, 2018).

Delacroix, Christian, Dosse, François, y Garcia, Patrick (dir.), Nicolas Offenstadt) Historiographies. Concepts et débats, Paris, Gallimard, coll. «Folio histoire», 2010, 2 vols.

Escudero Alday, Rafael (coord.), Diccionario de memoria histórica. Conceptos contra el olvido, Madrid, Catarata, 2011.

Ferro, Marc, Le ressentiment dans l'histoire. Comprendre notre temps. París, Odile Jacob, 2007.

Franco, Marina, Un enemigo para la nación, Orden interno, violencia y «subversión», 1973-1976, Buenos Aires, Fondo de Cultura Económica, 2012.

au passé... cit, p. 272; Traverso, Enzo, Mélancolie de gauche. La force d'une tradition cachée (XIXe-XXI' siècles), Paris, Editions La Découverte, 2016; Ricœur, Paul, La mémoire, l'bistoire, l'oubli, Paris, Seuil, 2000; Rousso, H., Face au passé..., cit., Interview a Henry Rousso, «Le surinvestissement dans la mémoire est une forme d'impuissance», Libération, 8/4/2016, <https://www.liberation.fr/debats/2016/04/08/henry-rousso-le-surinvestissement-dans-la-memoire-est-une-forme-d-impuissance_1444888>. 
Gárate Château, Manuel, «Las polémicas en torno al Museo de la Memoria y los Derechos Humanos en Chile», Carnet de l'IHTP, 21/11/2015 https://ihtp.hypotheses.org/1350>.

Garavaglia, Juan Carlos, Una juventud en los años sesenta, Buenos Aires, Prometeo Libros, 2015.

García Cárcel, Ricardo, La berencia del pasado. Las memorias históricas de España, Barcelona, Galaxia Gutenberg, 2012.

Garcia, Patrick, «Essor et enjeux de l'histoire du temps présent au CNRS», La revue pour l'bistoire $d u$ CNRS, n. ${ }^{\circ}$ 9, 2003, <http://journals.openedition.org/histoire-cnrs/562>.

—, «Essor et enjeux de l'histoire du temps présent au CNRS», La revue pour l'bistoire du CNRS, n. ${ }^{\circ}$ 9-2003, <http://histoire-cnrs.revues.org/562>.

Guénard, Florent, Le ressentiment passion sociale. Rennes, PUR, 2012.

Hartog, François, Régimes d'bistoricité. Présentisme et expériences du temps, Paris, Seuil, 2003.

Laclau, Ernesto, La razón populista, Buenos Aires, FCE, 2005.

Langue, Frédérique, «Usos del pasado y guerra de las memorias en la Venezuela de la «Segunda Independencia», Polis, Revista Latinoamericana (Chile), n. ${ }^{\circ} 34$, avril 2013, <https://journals. openedition.org/polis/8953>.

—, «Desafíos y retos de la historia del tiempo presente», Dalla Corte, Gabriela; Ricardo Piqueras; Meritxell Tous Mata (coords.), Construcción social y cultural del poder en las Américas, Barcelona, Universidad de Barcelona —Edición Km 13774- Fundació Casa América Catalunya, 2015, pp. 12-32. <http://www.americat.cat/es/construccion-social-y-cultural-del-poder-en-las-americas_es>.

Langue, Frédérique, «Cuba: d>un anniversaire oublié à la visite de Barack Obama», Le Huffington Post, 25/03/2016 <http://www.huffingtonpost.fr/frederique-langue/cuba-dun-anniversaireoublie-a-la-visite-de-barack-obama_b_9545488.html>.

—, «Un pasado que no pasa: emociones y salvación en la Venezuela del tiempo presente », Boletín Americanista, n. ${ }^{\circ} 72,2016$, pp. 237-256 <http://revistes.ub.edu/index.php/BoletinAmericanista/article/view/16052>.

—, «Bolivarianismos de papel», Revista de Indias, vol. LXXVII, n. ${ }^{\circ} 270,2017$, pp. 357-378<http:// revistadeindias.revistas.csic.es/index.php/revistadeindias/article/view/1047/1119>.

Langue, Frédérique y Edgardo Manero, «Repenser les populismes en Amérique latine et au-delà. Des figures du conflit à la guerre des mémoires», Revue ILCEA, n. ${ }^{\circ} 18,2013$, Université Stendhal, Grenoble 3, <https://journals.openedition.org/ilcea/2103>.

Mouffe, Chantal, Pour un populisme de gauche, Paris, Albin Michel, 2018.

Noiriel, Gérard, «Le» passé/présent»: une approche différente de l'histoire du temps présent», État, nation et immigration, Paris, Gallimard/Folio, 2005, pp. 70-101.

Pérotin, Anne (coord.), Historizar el pasado vivo en América Latina, 2007, <http://www.historizarelpasadovivo.cl>.

Pino Iturrieta, Elías, El divino Bolivar. Ensayo sobre una religión republicana. Madrid, Ed. de la Catarata, 2003.

Rangel, Carlos, Del buen Salvaje al Buen Revolucionario, Caracas, Monte Avila, 1976.

Ricœur, Paul, La mémoire, l'bistoire, l'oubli, Paris, Seuil, 2000 (La memoria, la historia, el olvido, Buenos Aires, FCE, 2004).

Rojas, Rafael, «Anatomía del entusiasmo: la revolución como espectáculo de ideas», América Latina Hoy, n. ${ }^{\circ}$ 47, 2009 <http://revistas.usal.es/index.php/1130-2887/article/view/2048>.

Rousso, Henry, La dernière catastrophe. L'bistoire, le présent, le contemporain, Paris, Gallimard, 2012 (Ed. española Santiago de Chile, Editorial Universitaria, 2018. 
—, Face au passé, Paris, Belin, 2016.

—, La hantise du passé. Entretien avec Philippe Petit, Paris, Textuel, 1998.

Soler, Lorena, Paraguay, la larga invención del golpe. El stronismo y el orden político paraguayo. Buenos Aires, Imago Mundi, 2012.

Traverso, Enzo, Mélancolie de gauche. La force d'une tradition cachée (XIX'-XXI siècles), Paris, Editions La Découverte, 2016.

Uzcátegui, José Luis, Chávez, mago de las emociones. Análisis psicosocial de un fenómeno político, Caracas, Lithopolar Gráficas, 1999.

Verdés-Leroux, Jeanin, La foi des vaincus. Les «révolutionnaires «français de 1945 à 2005, Paris, Fayard, 2005.

Voldman, Danièle, «Le témoignage dans l'histoire du temps présent», Bulletin de l'IHTP, n. ${ }^{\circ} 75$, julio 2000, Dossier - L'histoire du temps présent, hier et aujourd'hui, <http:/www.cmtra.org/ avec/lib/elfinder-2.0-rc1/files/NOS\%20ACTIONS/Publications/Dossiers\%20documentaires/ Archives \%20sonores/la \%20fabrique \%20du\%20témoin/VOLDMAN_Institut \%20d \%20histoire \%20du \%20temps \%20présent \%20-\%20IHTP\%20-\%20Le \%20témoignage \% 20 dans $\% 201 \% 20$ histoire $\% 20$ française $\% 20 \mathrm{du} \% 20$ temps $\% 20$ présent.pdf $>$.

Wievorka, Annette, L'ère du témoin, Paris, Pluriel, 2013.

Zago, Angela, La rebelión de los ángeles, Caracas, Warp Ediciones, 1998 (4. ${ }^{\mathrm{a}}$ ed.). 